and $25 \%$ had hyperleukocytosis. 2 patients had already taken antibiotics before admission. Group 2 included 13 patients, their mean PCT was $0.025 \mathrm{ng} / \mathrm{mL}(0.01-$ 0.13), mean CRP was $132.25 \mathrm{mg} / \mathrm{L}$, mean ESR was $84.38 \mathrm{~mm}$, and $30.77 \%$ of them had hyperleukocytosis. Group 3 included 3 patients, their mean PCT was $66.88 \mathrm{ng} / \mathrm{mL}(0.02-200)$, mean CRP was $560 \mathrm{mg} / \mathrm{L}$, mean ESR was $107.33 \mathrm{~mm}$, and $33.33 \%$ had hyperleucocytosis. The patient with the highest PCT was admitted for a sepsis with uremic encephalopathy that improved after hemodialysis. A control PCT was made in 2 patients with infection who received antibiotics, showing a decrease or negativation compared to the initial value of PCT.

Conclusion: Our study showed that PCT levels only increased significantly in bacterial infections. The PCT values were more discriminating than the level of WBC and CRP in differentiating a bacterial infection from another inflammatory process, hence the value of using this marker in case diagnosis doubt.

Disclosure of Interests: None declared

DOI: 10.1136/annrheumdis-2021-eular.3191

\section{POS1368 ANTI-IL-1 THERAPIES IN COLCHICINE-RESISTANT OR İNTOLERANT PATIENTS WITH FAMILIAL MEDITERRANEAN FEVER: SINGLE CENTER EXPERIENCE}

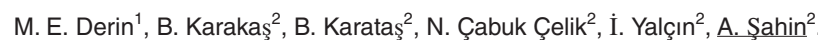

${ }^{1}$ Sivas Numune Hospital, Internal Medicine - Rheumatology, Sivas, Turkey;

${ }^{2}$ Sivas Cumhuriyet University, Internal Medicine - Rheumatology, Sivas, Turkey

Background: Familial Mediterranean Fever (FMF) is a hereditary auto-inflammatory disease characterized by recurrent fever and serosal inflammation (1). The goal of FMF treatment is to prevent the attacks and to minimize subclinical inflammation between attacks The main treatment of FMF is colchicine however anti-interleukin-1 treatments are recommended in colchicine resistant and/or intolerant FMF patients (2).

Objectives: The aim of this study is to evaluate the efficacy of anti-interleukin-1 (anti-IL-1) agents in 81 FMF patients with resistant/intolareted to colchicine or complicated with amyloidosis.

Methods: Between January 2014 and December 2020, eighty-one patients who were diagnosed as FMF according to the criteria of Tel-Hashomer that following-up at Cumhuriyet University Medical Faculty Rheumatology-Internal Medicine Department were included in to the study.

Results: $45(55.6 \%)$ male and $36(44.4 \%)$ female were included in the study. The median age of the patients was 25 years (min:17-max: 60 ) and the median age at diagnosis was 15 years ( $\min 3$-max 46 ). 44 patients (54.3\%) used Anakinra (100 mg/day), and $27(45.7 \%)$ canakinumab (150mg/8month) were used. 49 cases were resistant to colchicine, 16 were intolerant to colchicine, $16(20 \%)$ cases were comlicated with amyloidosis. 10 patients had renal transplantation. MEFV gene mutations are shown in Table 1. Median duration of anti-IL-1 agent use was 24 month (min:4-max 52). 9 patients were resistant to anakinra, 18 patients had side effects which anakinra related. After a median follow up 12 months overall clinical response was $\% 95$ (frequency of attacks $<1 / 6$ months). median proteinuria decreased from $3500 \mathrm{mg} /$ day to median $1500 \mathrm{mg} /$ day (p: 0.04) (Table 2). IL-6 treatment was started in 4 patients because of ineffective canakinumab. Five pregnant patients were followed up with anakinra during pregnancy and there were no problems.

Conclusion: Anti-interleukin-1 agents are effectively and safely in the treatment of FMF patients. There are still unanswered questions in FMF treatment such as other factors affecting the frequency of attacks, colchicine resistance is not defined precisely and the importance of some mutations. The effect of anti IL-1 agents on FMF patients with amyloidosis is not clearly. According to our experience, these treatments are effective in patients with glomerular filtration rate> $60 \mathrm{ml} / \mathrm{min}$. For answers to these and similar questions, Large and long follow-up studies are needed for long-term effects.

\section{REFERENCES:}

[1] Özen S, Batu ED, Demir S., Familial Mediterranean Fever: Recent Developments in Pathogenesis and New Recommendations for Management. Front Immunol. 2017 Mar 23;8:253. doi: 10.3389/fimmu.2017.00253. eCollection 2017.

[2] Seza Özen ve ark. EULAR recommendations for the management of familial Mediterranean fever. Ann Rheum Dis. 2016 Apr;75(4):644-51.

Disclosure of Interests: None declared

DOI: 10.1136/annrheumdis-2021-eular.3257

\section{POS1369 ADULT-ONSET STILL'S DISEASE: A SINGLE-CENTER EXPERIENCE}

B. Egeli' ${ }^{1}$, S. Ugurlu'2. 'Boston Children's Hospital, Immunology, Boston, United States of America; ${ }^{2}$ Istanbul University-Cerrahpasa, Internal Medicine, Istanbul, Turkey
Background: Adult-Onset Still's disease (AOSD) is an autoinflammatory condition characterized by fever, rash, and arthritis. The diagnosis of AOSD is made by excluding common causes of fever of unknown origin which are infections malignancies, autoimmune conditions and medication adverse effects. As it is a diagnostic challenge, further data on highlighting clinical and laboratory findings are necessary on guiding clinicians.

Objectives: Our main objective is to present our single tertiary center experience of patients diagnosed with AOSD.

Methods: This retrospective study was conducted at a tertiary rheumatology center. Patients were diagnosed with AOSD using Yamaguchi's criteria and followed between 2007 and 2020. Demographic, clinical and laboratory information was retrieved from the patient chars. Treatment-related and prognostic information were also noted with additional information from phone call interviews.

Results: The study includes 69 patients $(23 \mathrm{M}, 46 \mathrm{~F})$. The mean age of diagnosis was $33.86 \pm 14.3$. The presenting signs and symptoms of the patients are shown in Figure 1. The laboratory findings supporting the diagnosis at initial encounter are summarized in Table 1. The mean corticosteroid dose at initial diagnosis was $29.7 \pm 18 \mathrm{mg}$. In addition to corticosteroid treatment these patients were followed with different glucocorticoid-sparing agents. Methotrexate was the choice of treatment in 54 patients with the mean dose of $14.5 \pm 3.43 \mathrm{mg}$. Eight patients were treated with leflunomide, seven with anti-TNF agents, seven with tocilizumab, nineteen with anakinra and four with canakinumab.

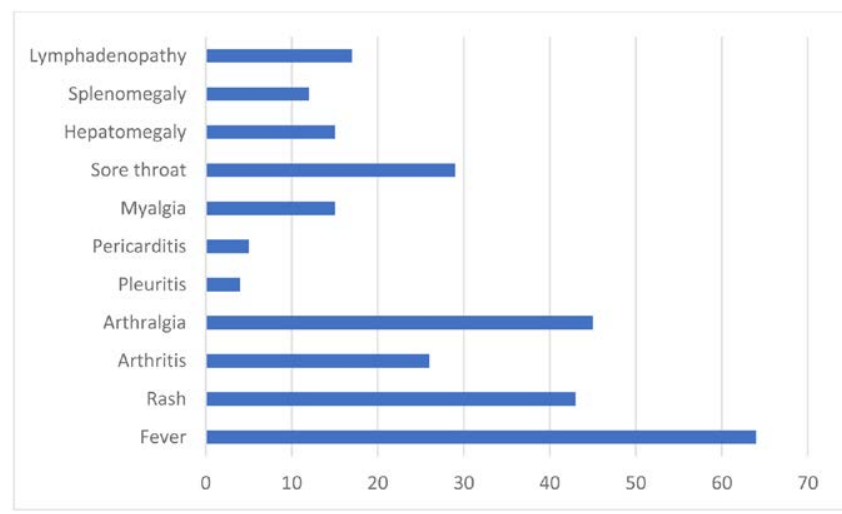

Figure 1. The presenting signs and symptoms of the patients

Conclusion: In conclusion, the most common presenting symptoms in our AOSD cohort were fever and salmon-colored rash. In the differential diagnosis of fever of unknown origin especially with rash, AOSD should be considered. Corticosteroid was the main treatment modality. In patients who are unresponsive to conventional immunosuppressive treatment, biologic agents can be an alternative.

Table 1. The laboratory findings at initial encounter

\begin{tabular}{lc}
\hline & Mean \pm Standard Deviation \\
\hline Ferritin $(\mathrm{ng} / \mathrm{mL})$ & $3179.46 \pm 6503.56$ \\
ESR $(\mathrm{mm} / \mathrm{h})$ & $77.43 \pm 28.47$ \\
CRP $(\mathrm{mg} / \mathrm{L})$ & $102.29 \pm 70.39$ \\
Leukocyte Count (cells/L) & $13147.3 \pm 4640.9$ \\
ESR $(\mathrm{mm} / \mathrm{h})$ & $80 \pm 28.48$ \\
CRP $(\mathrm{mg} / \mathrm{L})$ & $105.15 \pm 54.67$ \\
Leukocyte Count (cells/L) & $12427.14 \pm 6530.43$ \\
\hline
\end{tabular}

Disclosure of Interests: None declared

DOI: 10.1136/annrheumdis-2021-eular.3280

\section{POS1370}

HYDROXYCLOROQUINE-INDUCED ATRIOVENTRICULAR BLOCK IN IMMUNE-MEDIATED DISEASES. SINGLE UNIVERSITY CENTER STUDY OF 293 PATIENTS

A. Herrero-Morant ${ }^{1}$, A. Margarida-de Castro ${ }^{1}$, R. Pérez-Barquín ${ }^{1}$, J. ZubiaurZamacola ${ }^{1}$, M. Á. González-Gay ${ }^{1}$, R. Blanco ${ }^{1} .{ }^{1}$ Hospital Universitario Marqués de Valdecilla, Rheumatology and Cardiology, Santander, Spain

Background: Hydroxychloroquine (HCQ) is an extensively used drug in immune-mediated diseases (IMID). Despite its general safety, HCQ can cause serious toxicity such as heart conduction disorders. Atrioventricular block (AVB) 